\title{
$m$-lodosylbenzoic acid - a convenient recyclable reagent for highly efficient aromatic iodinations
}

\author{
Andreas Kirschning ${ }^{*}$, Mekhman S. Yusubov ${ }^{*}$, Roza Y. Yusubova ${ }^{2}$, \\ Ki-Whan $\mathrm{Chi}^{3}$ and Joo Y. Park ${ }^{3}$
}

\section{Full Research Paper}

\section{Address:}

${ }^{1}$ Institut für Organische Chemie and Zentrum für Biomolekulare Wirkstoffchemie (BMWZ), Leibniz Universität Hannover, Schneiderberg 1B, D-30167 Hannover, Germany, ${ }^{2}$ The Siberian State Medical University, 2 Moskovsky trakt, 634050 Tomsk, Russia and The Tomsk Polytechnic University, 30 Lenin st., 634050 Tomsk, Russia and ${ }^{3}$ University of Ulsan, 680-749 Ulsan, Republic of Korea

\section{Email:}

Andreas Kirschning ${ }^{*}$ - andreas.kirschning@oci.uni-hannover.de; Mekhman S. Yusubov - yusubov@mail.ru; Roza Y. Yusubova I_yusubova@mail.ru; Ki-Whan Chi - kwchi@mail.ulsan.ac.kr; Joo Y.Park - kwchi@mail.ulsan.ac.kr

* Corresponding author
Beilstein Journal of Organic Chemistry 2007, 3, No. 19 doi:10.1186/1860-5397-3-19

Received: 02 April 2007

Accepted: 04 June 2007

Published: 04 June 2007

() 2007 Kirschning et al; licensee Beilstein-Institut. License and terms: see end of document.

\begin{abstract}
$m$-Iodosylbenzoic acid performs iodinations of arenes in the presence of iodine at room temperature in acetonitrile. Separation of pure products is conveniently achieved by scavenging any aryl iodide by ion exchange with IRA-900 (hydroxide form). The reduced form of the reagent, $m$-iodobenzoic acid, can be easily recovered from the ion exchange resin or from the basic aqueous solution by simple acidification with $\mathrm{HCl}$.
\end{abstract}

\section{Background}

In recent years, iodoarenes have gained increasing importance because they are widely used as building blocks in organic synthesis. They are particularly important as indispensable substrates for numerous methods of $\mathrm{N}-\mathrm{N}$ bond formation, $[1,2]$ for the chemistry of heterocyclic [3] and organometallic compounds, [4-8] and for the synthesis of polyvalent iodine organic compounds. $[9,10]$ In addition, polyvalent organoiodine compounds have served as cooxidants in the iodination of arenes. [11-36] Typical polyvalent iodine sources for these iodination reactions are reagents $\mathbf{1}-\mathbf{4}$ (Figure 1). Iodosylbenzene $\mathbf{5}$ is not suitable for iodinations because of its low activity. [37]

In this report we describe a practical improvement for these iodinations as far as purification of the products and recycling of the iodine reagent is concerned. The broad use of hypervalent iodine reagents is still hampered by tedious purification and recycling protocols. Commonly, purification relies on chro- 




Figure 1: Hypervalent iodine reagents $1-6$.

matography. Recently, tagging strategies for reagents and catalysts have widely been investigated that allow easy purification by means of specific phase separation or scavenging. [39-41]

\section{Results and discussion}

In this context, we recently described an improved procedure for the preparation of the hardly known $m$-iodosylbenzoic acid 6 and showed that it is a recyclable reagent for the highly efficient $\mathrm{RuCl}_{3}$-catalyzed oxidation of alcohols to aldehydes and ketones. [42] In the present work we demonstrate the utility of $m$-iodosylbenzoic acid $\mathbf{6}$ as a recyclable reagent for the iodination of arenes. In fact reagent 6 can be regarded as a tagged version of iodoso benzene $\mathbf{5}$ which, if used in access, can be conveniently removed at the end of the reaction by filtration after addition of IRA 900 (hydroxide form) (Scheme 1). This scavenging concept can also be applied to reduction products such as $m$-iodobenzoic acid $\mathbf{9}$. Importantly, 9 which also serves as the starting material for the preparation of $\mathbf{6}$ can easily be regenerated $(>95 \%)$ from polymer $\mathbf{1 0}$ in pure form by treatment with aqueous $\mathrm{HCl}$.

We found that the reaction of aromatic substrates 7a-o with $\mathrm{I}_{2}$ and 6 in $\mathrm{CH}_{3} \mathrm{CN}$ (commonly in the presence of 50\% aqueous $\mathrm{H}_{2} \mathrm{SO}_{4}$ ) led to the corresponding iodinated arenes in $40-99 \%$ yield under mild conditions (Scheme 1 and Table 1 and Table 2). Addition of aqueous $\mathrm{H}_{2} \mathrm{SO}_{4}$ accelerated the iodination of benzenes. For heteroarenes $\mathbf{7 j}$ and $7 \mathbf{0}$ this additive was not required and if an additional alcohol group was present (see $7 \mathbf{n}$ ), addition of aqueous $\mathrm{H}_{2} \mathrm{SO}_{4}$ resulted in its oxidation. Compared to diacetoxyiodobenzene (DIB) 1a and its polymeric analog $\mathbf{1 b}$, the use of $m$-iodosylbenzoic acid $\mathbf{6}$ for mono- and diiodination requires the use of smaller amounts of iodine as well as of the polyvalent iodine reagent. [15] For example, the

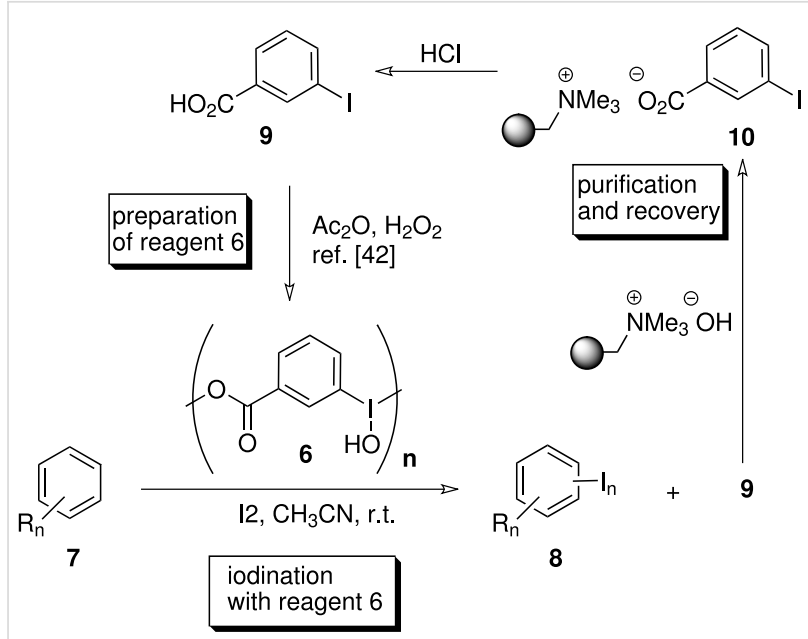

Scheme 1: lodine(III)-promoted iodination of arenes and concept of purification.

preparation of 2,4-diiodoanisole $\mathbf{8 k}$ from anisole $7 \mathbf{k}$ in the presence of $\mathbf{1 b}$ was achieved using 4.8 equiv. of both iodine and $\mathbf{1 b}$ while our iodination protocol required only 2.4 equiv. of iodine and 1.2 equiv. of $m$-iodosylbenzoic acid $\mathbf{6}$.

Likewise, for the preparation of aryliodide 8c a 2.4 molar excess of both iodine and reagent 1a had to be employed while in our case 1.2 equiv. of iodine and 1.2 equiv. of reagent 6 were required for full conversion.

As is evident from the tables, iodination of arenes that are acylated like $7 \mathbf{d}, \mathbf{e}, \mathbf{g}$ and $7 \mathbf{i}$ commonly led to excellent yields of selectively iodinated arenes $\mathbf{8 d}, \mathbf{e}, \mathbf{g}$ and $\mathbf{8 i}$. Increasing the nucleophilicity of the aromatic ring such as in 3,5-dimethoxybenzyl alcohol $7 \mathbf{n}$ led to diiodinated benzyl alcohol $\mathbf{8 n}$ in good yield. Oxidation of the alcohol group was not observed.

Based on related iodine(III)-mediated iodinations of arenas [12-37] we suggest that the hydrated form of 6 oxidizes iodine to HOI which serves as the reactive electrophilic intermediate (Scheme 2).

From the results collected it can be concluded that $m$-iodosylbenzoic acid 6 shows a similar reactivity as 1-(arenesulf-

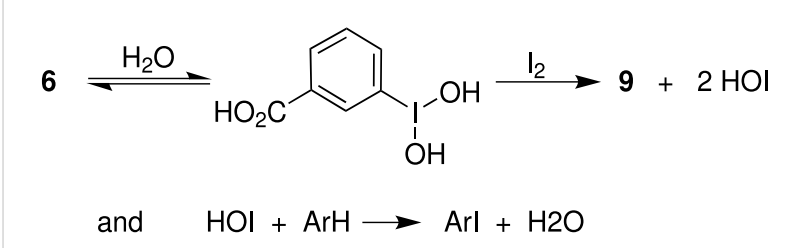

Scheme 2: Proposed intermediates. 
Table 1: Monoiodination of arenes with $m$-iodosylbenzoic acid 6 (see Supporting Information File 1 for full experimental data).

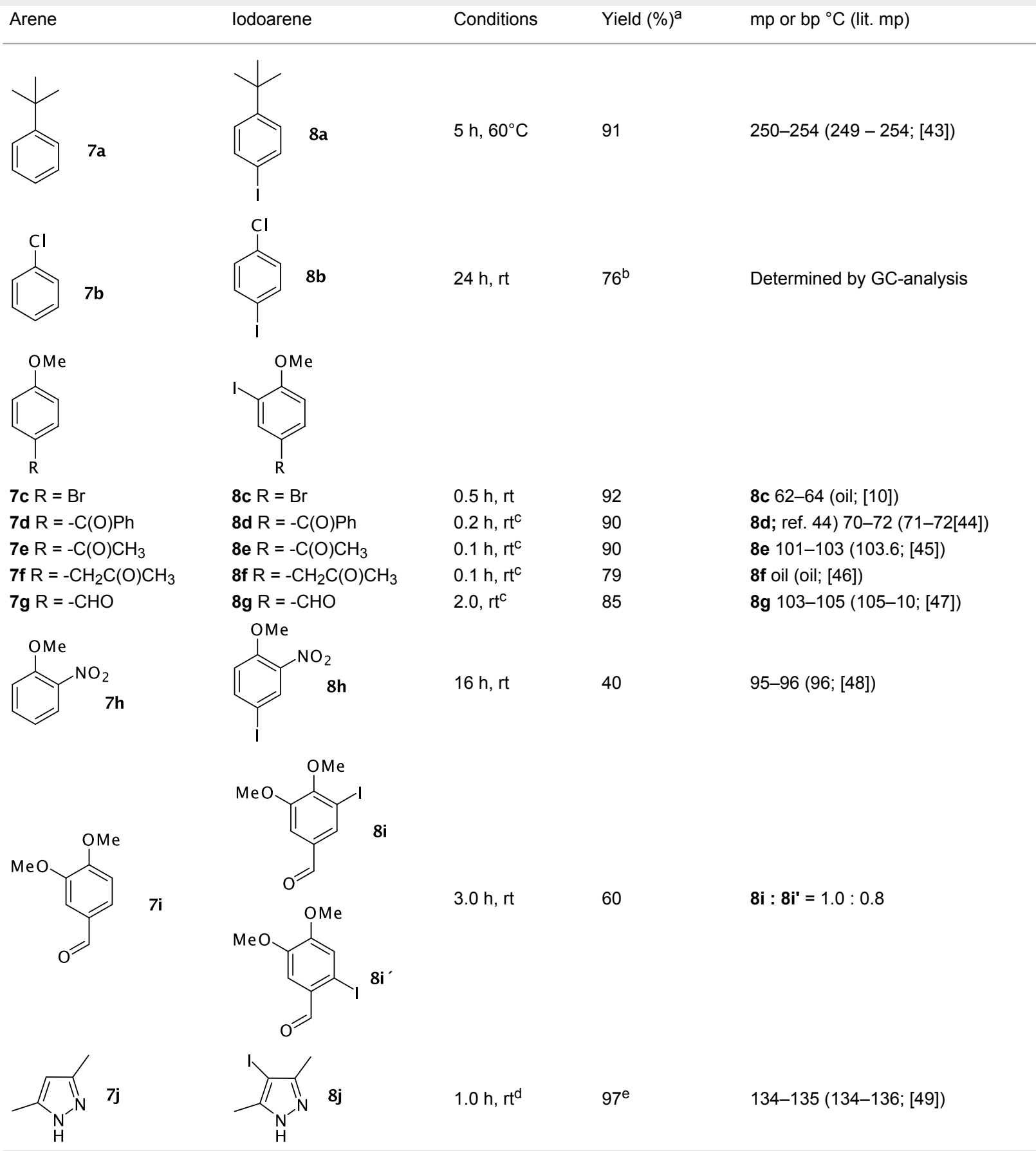

a Molar ratio $\mathrm{ArH} / 6 /$ iodine $0.2 / 0.24 / 0.12$ (in mmol) and $0.05 \mathrm{~mL}$ aq. $(50 \%) \mathrm{H}_{2} \mathrm{SO}_{4}$; isolated yields. ${ }^{b}$ Determined by $\mathrm{GC}$-analysis. ${ }^{\mathrm{C}}$ Instead of $0.05 \mathrm{~mL}$ only $0.02 \mathrm{~mL}$ aq. $(50 \%) \mathrm{H}_{2} \mathrm{SO}_{4}$ was added. ${ }^{d} \mathrm{No}$ aq. $(50 \%) \mathrm{H}_{2} \mathrm{SO}_{4}$ was added. ${ }^{e} \mathrm{NaHCO}_{3}$ was used instead of IRA 900 (hydroxide form).

onyloxy)benziodoxolones 4a-f [36,37]. However, reagent $\mathbf{6}$ is cheaper and exerts better selectivity in the iodination reactions.

\section{Conclusion}

In conclusion, we disclose that the rarely employed $m$-iodosylbenzoic acid is an ideal tagged iodine(III) reagent which in our view allows the easiest purification protocol for aryliodine reagents known so far. This tagging concept was utilized in the mild iodination of arenes but could potentially be applied to most other iodine(III)-mediated reactions. 
Table 2: Diiodination of Arenes with $m$-lodosylbenzoic acid 6 (see Supporting Information File 1 for full experimental data).



a Isolated yields. ${ }^{b}$ Molar ratio ArH/6/iodine 0.2/0.48/0.24 (in mmol) and $0.05 \mathrm{~mL}$ aq. $(50 \%) \mathrm{H}_{2} \mathrm{SO}_{4} .{ }^{c} \mathrm{No}$ aq. $(50 \%) \mathrm{H}_{2} \mathrm{SO}_{4}$ was added. ${ }^{\mathrm{d}} \mathrm{NaHCO}_{3}$ was used instead of IRA 900 (hydroxide form).

\section{Supporting Information}

\section{Supporting Information File 1}

Experimental details. The data provide general experimental details as well as an improved procedure for the preparation of m-iodosylbenzoic acid (6), a typical iodination procedure and spectroscopic and analytic data for $\mathbf{8 n}$.

[http://www.beilstein-journals.org/bjoc/content/ supplementary/1860-5397-3-19-S1.doc]

\section{Acknowledgments}

M. S. Y. thanks the Russian Ministry of Education and the Deutsche Akademische Austauschdienst (DAAD) for a scholarship and RFBR (Grant 07-03-12141-ofi). Additionally, the work was funded by the Fonds der Chemischen Industrie. Ki-Whan Chi thanks the University of Ulsan Research Fund 2006. We are grateful to Prof. Viktor Filimonov from Tomsk Polytechnic University for helpful discussions.

\section{References}

1. Hiyama, T. Organosilicon Compounds in Cross-Coupling Reactions. In Metal-catalyzed cross-coupling reactions; Diederich, F.; Stang, P. J., Eds.; Wiley-VCH: Weinheim, 1998; pp 421-453.

2. Comprehensive Organic Synthesis. Trost, B. M., Ed.; Pergamon: Oxford, UK, 1991; Vol. 3, pp 521-549.

3. Cacchi, S.; Fabrizi, G. Chem. Rev. 2005, 105, 2873-2920. doi:10.1021/cr040639b

4. Hassan, J.; Sévignon, M.; Gozzi, C.; Schulz, E.; Lemaire, M. Chem. Rev. 2002, 102, 1359-1470. doi:10.1021/cr000664r

5. Beletskaya, I. P.; Cheprakov, A. V. Chem. Rev. 2000, 100, 3009-3066. doi:10.1021/cr9903048

6. Kotha, S.; Lahiri, K.; Kashinath, D. Tetrahedron 2002, 58, 9633-9695. doi:10.1016/S0040-4020(02)01188-2

7. Bellina, F.; Carpita, A.; Rossi, R. Synthesis 2004, 2419-2440. doi:10.1055/s-2004-831223

8. Knochel, P.; Dohle, W.; Gommermann, N.; Kneisel, F. F.; Kopp, F.; Korn, T.; Sapountzis, I.; Vu, V. A. Angew. Chem. 2003, 115, 4438-4456. doi:10.1002/ange.200300579 Angew. Chem., Int. Ed. 2003, 42, 4302-4320. doi:10.1002/ anie.200300579.

9. Moriarty, R. M. J. Org. Chem. 2005, 70, 2893-2903. doi:10.1021/ jo050117b 
10. Wirth, T. Angew. Chem. 2005, 117, 3722-3731. doi:10.1002/ ange.200500115

Angew. Chem., Int. Ed. 2005, 44, 3656-3665. doi:10.1002/ anie. 200500115.

11. Ogata, Y.; Aoki, K. J. Am. Chem. Soc. 1968, 90, 6187-6191. doi:10.1021/ja01024a043

12. Kryska, A.; Skulski, L. J. Chem. Res., Synop. 1999, 590-591. doi:10.1039/a904053f

13. Giri, R.; Chen, X.; Yu, J.-Q. Angew. Chem. 2005, 117, 2150-2153. doi:10.1002/ange.200462884

Angew. Chem., Int. Ed. 2005, 44, 2112-2115. doi:10.1002/ anie.200462884.

14. Krasnokutskaya, E. A.; Trusova, M. E.; Filimonov, V. D. Zh. Org. Khim. 2005, 41, 1788-1789.

Russ. J. Org. Chem. 2005, 41, 1750-1751.

15. Togo, H.; Nogami, G.; Yokoyama, M. Synlett 1998, 534-536. doi:10.1055/s-1998-1713

16. Togo, H.; Nabana, T.; Yamaguchi, K. J. Org. Chem. 2000, 65, 8391-8394. doi:10.1021/jo001186n

17. Boyer, J. H.; Natesh, A. Synthesis 1988, 980-981. doi:10.1055/s-198827774

18. Yudina, N. D.; Raida, V. S.; Vasil'eva, O. L.; Deniskin, V. V.; Stepanets, M. P.; Sitnikov, A. S. Polym. Sci. USSR 1989, 31, 1318-1321. doi:10.1016/0032-3950(89)90159-7

19. Vasil'eva, O. L.; Raida, V. S.; Sirotkina, E. E. Vysokomol. Soedin., Ser. A 1992, 34, 131-134.

20. D'Auria, M.; Mauriello, G. Tetrahedron Lett. 1995, 36, 4883-4884.

21. Boyle, R. W.; Johnson, C. K.; Dolphin, D. J. Chem. Soc., Chem. Commun. 1995, 527-528.

22. D'Auria, M.; de Luca, E.; Mauriello, G.; Racioppi, R.; Sleiter, G. J. Chem. Soc., Perkin Trans. 11997, 2369-2374. doi:10.1039/a701674c

23. Lambert, C.; Nöll, G. Angew. Chem. 1998, 110, 2239-2242. doi:10.1002/(SICI)1521-3757(19980803)110:15<2239::AIDANGE2239>3.0.CO;2-H

Angew. Chem., Int. Ed. 1998, 37, 2107-2110. doi:10.1002/(SICI)15213773(19980817)37:15<2107::AID-ANIE2107>3.0.CO;2-H.

24. Benhida, R.; Blanchard, P.; Fourrey, J.-L. Tetrahedron Lett. 1998, 39, 6849-6852. doi:10.1016/S0040-4039(98)01494-4

25. Shanmugathasan, S.; Johnson, C. K.; Edwards, C.; Matthews, E. K.; Dolphin, D.; Boyle, R. W. J. Porphyrins Phthalocyanines 2000, 4, 228-232. doi:10.1002/(SICI)1099-1409(200004/05)4:3<228::AIDJPP199>3.0.CO;2-7

26. Miyaji, H.; Sato, W.; Sessler, J. L.; Lynch, V. M. Tetrahedron Lett. 2000, 41, 1369-1373. doi:10.1016/S0040-4039(99)02295-9

27. Anzenbacher, P.; Jursikova, K.; Shriver, J. A.; Miyaji, H.; Lynch, V. M.; Sessler, J. L.; Gale, P. A. J. Org. Chem. 2000, 65, 7641-7645. doi:10.1021/j0005610w

28. Yu, L.; Lindsey, J. S. Tetrahedron 2001, 57, 9285-9298. doi:10.1016/ S0040-4020(01)00928-0

29. Füchtner, F.; Angelberger, P.; Kvaternik, H.; Hammerschmidt, F.; Simovc, P.; Steinbach, J. Nucl. Med. Biol. 2002, 29, 477-481. doi:10.1016/S0969-8051(02)00298-6

30. Tomizaki, K.-y.; Lysenko, A. B.; Taniguchi, M.; Lindsey, J. S. Tetrahedron 2004, 60, 2011-2023. doi:10.1016/j.tet.2004.01.003

31. Taniguchi, M.; Kim, M. N.; Ra, D.; Lindsey, J. S. J. Org. Chem. 2005, 70, 275-285. doi:10.1021/jo048440m

32. Jin, L.-M.; Chen, L.; Yin, J.-J.; Zhou, J.-M.; Giu, C.-C.; Chen, Q.-Y. J. Org. Chem. 2006, 71, 527-536. doi:10.1021/jo051672g

33. Hashimoto, M.; Kato, Y.; Hatanaka, Y. Tetrahedron Lett. 2006, 47, 3391-3394. doi:10.1016/j.tetlet.2006.03.068
34. Bovonsombat, P.; Angara, G. J.; McNelis, E. Synlett 1992, 131-132. doi:10.1055/s-1992-21290

35. Bovonsombat, P.; Djuardi, E.; McNelis, E. Tetrahedron Lett. 1994, 35, 2841-2844. doi:10.1016/S0040-4039(00)76639-1

36. Muraki, T.; Togo, H.; Yokoyama, M. Synlett 1998, 286-288. doi:10.1055/s-1998-1639

37. Muraki, T.; Togo, H.; Yokoyama, M. J. Org. Chem. 1999, 64, 2883-2889. doi:10.1021/jo9825207

38. Sohmiya, H.; Kimura, T.; Fujita, M.; Ando, T. Tetrahedron 1998, 54, 13737-13750. doi:10.1016/S0040-4020(98)00844-8

39. Barrett, A. G. M.; Hopkins, B. T.; Köbberling, J. Chem. Rev. 2002, 102, 3301-3324. doi:10.1021/cr0103423

40. Yoshida, J.-i.; Itami, K. Chem. Rev. 2002, 102, 3693-3716. doi:10.1021/cr0103524

41. Bhattacharyya, S. Curr. Opin. Drug Discovery Dev. 2004, 7, 752-764.

42. Yusubov, M. S.; Gilmkhanova, M. P.; Zhdankin, V. V.; Kirschning, A. Synlett 2007, 563-566. doi:10.1055/s-2007-970742

43. Fields, E. K.; Meyerson, S. J. Org. Chem. 1978, 43, 4705-4708. doi:10.1021/jo00419a005

44. Bachki, A.; Foubelo, F.; Yus, M. Tetrahedron 1994, 50, 5139-5146. doi:10.1016/S0040-4020(01)90424-7

45. Bogert, M. T.; Curtin, L. P. J. Am. Chem. Soc. 1923, 45, 2161-2167. doi:10.1021/ja01662a020

46. Pavlinac, J.; Zupan, M.; Stavber, S. J. Org. Chem. 2006, 71, 1027-1032. doi:10.1021/jo052021n

47. Hart, D. J.; Hong, W.-P. J. Org. Chem. 1985, 50, 3670-3672. doi:10.1021/jo00219a061

48. Butler, A. R.; Sanderson, A. P. J. Chem. Soc., Perkin Trans. 2 1972, 989-992. doi:10.1039/p29720000989

49. Cheng, D.-P.; Chen, Z.-C.; Zheng, Q.-G. Synth. Commun. 2003, 33, 2671-2676. doi:10.1081/SCC-120021987

50. Orito, K.; Hatakeyama, T.; Takeo, M.; Suginome, H. Synthesis 1995, 1273-1277. doi:10.1055/s-1995-4089

51. Dickens, J. P.; Dyer, R. L.; Hamill, B. J.; Harrow, T. A.; Bible, R. H., Jr.; Finnegan, P. M.; Henrick, K.; Owston, P. G. J. Org. Chem. 1981, 46, 1781-1786. doi:10.1021/jo00322a005

\section{License and Terms}

This is an Open Access article under the terms of the Creative Commons Attribution License (http://creativecommons.org/licenses/by/2.0), which permits unrestricted use, distribution, and reproduction in any medium, provided the original work is properly cited.

The license is subject to the Beilstein Journal of Organic Chemistry terms and conditions: (http://www.beilstein-journals.org/bjoc)

The definitive version of this article is the electronic one which can be found at: doi:10.1186/1860-5397-3-19 